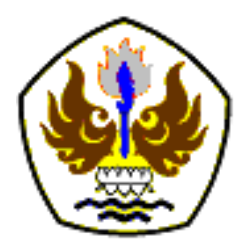

INFOMATEK

Volume 20 Nomor 2 Desember 2018

\title{
ANALISIS KESEDIAAN MEMBAYAR (WILLINGNESS TO PAY DAN KESEDIAAN UNTUK MENERIMA KOMPENSASI (WILLINGNESS TO ACCEPT) DARI KEBERADAAN TEMPAT PENAMPUNGAN SEMENTARA CIWASTRA DENGAN CONTINGENT VALUATION METHOD
}

\author{
Astri Hasbiah ${ }^{\star}$, Anni Rochaeni, Anto Firmansyah Sutopo \\ Prodi Teknik Lingkungan \\ Fakultas Teknik - Universitas Pasundan
}

\begin{abstract}
Abstrak: Laju pertumbuhan penduduk yang sangat pesat mengakibatkan meningkatnya konsumsi masyarakat, yang pada akhirnya berdampak pada bertambahnya jumlah timbulan sampah yang dihasilkan. Penelitian ini bertujuan untuk mengetahui kesediaan membayar WTP (Willingness to Pay), kesediaan menerima ganti rugi WTA (Willingness to Accept), dan nilai ekonomi dari keberadaan TPS dengan studi kasus Tempat Panampungan Sementara (TPS) Ciwastra Kelurahan Mekarjaya Kecamatan Rancasari Kota Bandung. Penelitian ini menggunakan metode contingent valuation methode (CVM) dengan sistem open ended question dan analisis regresi linier berganda untuk mengetahui faktor-faktor yang mempengaruhi besarnya nilai kesediaan membayar yang diberikan oleh masyarakat. Biaya retribusi pengelolaan sampah TPS Ciwastra adalah sebesar Rp 3.000,-/KK/bulan. Berdasarkan hasil perhitungan didapat nilai rata-rata WTP responden sebesar Rp 7.455,/KK/bulan, nilai total WTP responden sebesar Rp 30.240.100,-/bulan dan nilai $R^{2}$ WTP sebesar $72,3 \%$. Hasil perhitungan nilai WTP menunjukkan bahwa responden mampu untuk membayar lebih besar daripada biaya retribusi yang ditetapkan. Hal ini dapat digunakan sebagai dasar dalam upaya perbaikan pengelolaan persampahan di TPS Ciwastra. Nilai rata-rata WTA responden sebesar Rp 718.500,-/KK/bulan, nilai total WTA responden sebesar 2.918.190.000,-/bulan dan nilai $R^{2}$ WTA sebesar 94,94\%. Hasil dari perhitungan nilai ekonomi dari keberadaan TPS Ciwastra berdasarkan metode CVM sebesar Rp 940.129.300,-. Berdasarkan hasil regresi linier berganda diperoleh fungsi persamaan yaitu $\hat{Y}=46,5-0,028 X 1-0,190 \times 2+0,092 \times 3$. Dari hasil regresi didapatkan nilai koefisien determinasi Adjusted $R$ Square sebesar 2,5\%.
\end{abstract}

Kata kunci: Contingent Valuation Method, TPS Sampah, WTP, WTA

\section{PENDAHULUAN}

Permasalahan sampah perkotaan di Indonesia merupakan salah satu masalah yang belum terselesaikan secara tuntas. Tingkat

\footnotetext{
*) astrihasbiah@unpas.ac.id
}

Pertama diterima : 12 Oktober 2018

Direvisi : 13 Okober 2018

Disetujui untuk publikasi: 13 Oktober 2018 pelayanan pengelolaan sampah di Indonesia masih rendah (Meidiana dan Gamse [1]). Menurut data (PD Kebersihan Kota Bandung [2]) tahun 2015, timbulan sampah masyarakat Kota Bandung diproyeksikan sebesar 1.670 ton/hari dengan jumlah penduduk pada tahun 2015 sebanyak 2.783.367. Sampah yang 
terangkut ke Tempat Pemrosesan Akhir sampah (TPA) sebesar \pm 1100 ton/hari dan tingkat pelayanan pengangkutan sampah ke TPA baru mencapai 51,85\%. Menurut (Susanto dan Rahardyan [3]), pelayanan persampahan oleh PD Kebersihan Kota Bandung belum optimal karena terbatasnya dana subsidi dari pemerintah kota dan iuran sampah masyarakat yang rendah. Keterbatasan pembiayaan pengolahan sampah tersebut menyebabkan pelayanan pengolahan sampah tidak berjalan dengan baik (Ruban dkk [4]).

Sebagai upaya agar masyarakat tidak membuang sampah sembarangan karena alasan lokasi TPA yang terlalu jauh maka dibuatlah suatu tempat yang bernama TPS. TPS memiliki keuntungan yaitu memudahkan masyarakat untuk mengelola sampahnya sehingga tidak perlu mengharuskan masyarakat untuk membuang sampah ke TPA yang lokasinya biasanya jauh dari pemukiman, dan mencegah masyarakat untuk membuang sampah sembarangan. Selain keuntungan yang dimiliki TPS, adapun kerugian yang ditimbulkan oleh keberadaan TPS, adalah timbulnya bau tak sedap, lalat, nyamuk dan lain sebagainya.

TPS Ciwastra merupakan fasilitas yang digunakan bagi masyakarat Kelurahan
Mekarjaya sebagai tempat sebelum sampah diangkut ke tempat pendauran ulang, pengolahan, dan/atau tempat pengolahan terpadu dengan luas $17 \times 18 \mathrm{~m}^{2}$. TPS Ciwastra didirikan pada tahun 2002 oleh PD Pasar Ciwastra yang dikelola langsung oleh PD Kebersihan Kota Bandung. Lokasi TPS Ciwastra berada di Komplek Perumahan Baturaden RT.01/RW.07 Kelurahan Mekarjaya Kecamatan Rancasari Kota Bandung.

Sumber sampah yang masuk ke TPS Ciwastra berasal dari $11 \mathrm{RW}$ yang berada di Kelurahan Mekarjaya, 41 RW dari Kecamatan Buahbatu, sampah dari pasar ciwastra dan institusi pendidikan. Jumlah kendaraan pengangkutan sampah yang dimiliki oleh TPS Ciwastra sebanyak 40 triseda kapasitas 1,5 m³, 4 truck kapasitas 10-12 $\mathrm{m}^{3}$, dan 1 motor penyiraman.

Oleh karena itu, penelitian ini bertujuan untuk mengetahui nilai WTP dan WTA dari responden yang berada disekitar lokasi TPS Ciwastra dengan menggunakan metoda Contingent Valuation Method (CVM). Metode CVM menggunakan pendekatan secara langsung yang pada dasarnya menanyakan kepada masyarakat berapa besarnya maksimum kesediaan untuk membayar (WTP) manfaat tambahan yang diperoleh dari penggunaan dan/atau berapa besarnya kesediaan untuk menerima (WTA) 
kompensasi dari penurunan kualitas barang lingkungan.

\section{METODOLOGI}

\section{Sumber Data}

Data yang dikumpulkan terdiri atas data primer dan sekunder.

a. Data Primer; diperoleh dengan cara wawancara melalui kuesioner.

b. Data Sekunder; diperoleh dari PD Kebersihan Kota Bandung, Kelurahan Mekarjaya dan studi literatur.

Pengambilan sample (responden) dalam penelitian ini dilakukan dengan metode simple random sampling yaitu pengambilan sampel anggota populasi dilakukan secara acak tanpa memperhatikan strata yang ada dalam populasi tersebut.

Penentuan jumlah sample dihitung menggunakan rumus slovin dengan rumus sebagai berikut :

$$
\mathbf{n}=\frac{N}{1+N e^{z}}
$$

Dimana :

$\begin{array}{ll}\mathrm{n} & =\text { Ukuran sampel } \\ \mathrm{N} & =\text { Ukuran populasi } \\ \mathrm{E} & =\text { Nilai kritis (batas penelitian) yang }\end{array}$ diinginkan (persen kelonggaran ketidak telitian karena kesalahan pengambilan sampel populasi)
Jumlah Kepala Keluarga yang diteliti adalah 4.070 dengan $e=10 \%$ maka akan didapatkan ukuran sampel sebanyak 100 .

\section{Analisis Data}

Terdapat beberapa tahap dalam penerapan analisis CVM, yaitu membuat pasar hipotetik, mendapatkan penawaran besarnya nilai WTA/WTP, memperkirakan nilai rata-rata WTP dan/atau nilai tengah WTA, memperkirakan kurva penawaran, menjumlahkan data, dan mengevaluasi penggunaan CVM.

Pasar hipotesis pada valuasi ini berdasarkan pada dampak positif dan negatif dari keberadaan TPS Ciwastra kepada masyarakat sekitar. Sedangkan teknik yang digunakan dalam penelitian ini adalah Open-ended question, yaitu metode pertanyaan terbuka dimana setiap individu ditanyakan nilai maksimum WTP dan WTA responden tanpa adanya nilai awal yang disarankan kepada responden.

Dugaan nilai (EWTP) yang bertujuan untuk menguji hasil perhitungan dari WTP rata-rata responden yang dihitung berdasarkan data distribusi WTP responden dihitung dengan menggunakan rumus:

$$
\text { EWTP }=\sum W i P f i
$$


Dimana :

$$
\begin{array}{ll}
\text { EWTP } & =\text { Dugaan rataan WTP } \\
\mathrm{Wi} & =\text { Nilai WTP ke-i } \\
\mathrm{Pfi} & =\text { Frekuensi Relatif } \\
\mathrm{n} & =\text { Jumlah responden } \\
\mathrm{i} & =\text { Responden ke-i yang bersedia }
\end{array}
$$
melakukan pembayaran jasa lingkungan

Nilai total (TWTP) responden dihitung berdasarkan data distribusi WTP responden dan dengan menggunakan rumus:

$$
\text { TWTP }=\sum_{i}^{n} W T P i\left(\frac{n i}{N}\right) \mathrm{P}
$$

Dimana:

TWTP $=$ Total WTP

WTPi = WTP individu sampel ke-i

$\mathrm{Ni}=$ Jumlah sampel ke-i yang bersedia membayar sebesar WTP

$$
\begin{array}{ll}
\mathrm{N} & =\text { Jumlah sampel } \\
\mathrm{P} & =\text { Jumlah populasi } \\
\mathrm{I} & =\text { Responden ke-i yang bersedia }
\end{array}
$$$$
\text { membayar pembayaran jasa lingkungan }
$$

Dugaan nilai (EWTA) dihitung berdasarkan data distribusi WTA dengan menggunakan rumus:

$$
\text { EWTA }=\sum W i P f i
$$

Dimana :

$$
\begin{array}{ll}
\text { EWTA } & =\text { Dugaan rataan WTA } \\
\mathrm{Wi} & =\text { Nilai WTA ke-i } \\
\mathrm{Pfi} & =\text { Frekuensi Relatif } \\
\mathrm{n} & =\text { Jumlah responden }
\end{array}
$$

$\mathrm{i}=$ Responden ke-i yang bersedia melakukan pembayaran jasa lingkungan

Nilai total (TWTA) responden dihitung berdasarkan data distribusi WTPA responden dan dengan menggunakan rumus:

$$
\text { TWTA }=\sum_{i}^{n} W T P i\left(\frac{n i}{N}\right) P
$$

\section{Dimana:}

TWTA $=$ Total WTA

WTAi = WTA individu sampel ke-i

$\mathrm{Ni} \quad=$ Jumlah sampel ke-i yang bersedia membayar sebesar WTA

$\mathrm{N}=$ Jumlah sampel

$\mathrm{P} \quad=$ Jumlah populasi

$\mathrm{I}=$ Responden ke-i yang bersedia membayar pembayaran jasa lingkungan

\section{ANALISIS DAN PEMBAHASAN}

\section{Analisis Willingness To Pay}

\section{Membangun Pasar Hipotesis (Setting-up}

\section{the Hypothetical Market)}

Pasar hipotesis yang dibangun pada penelitian ini adalah keberadaan TPS Ciwastra memiliki dampak positif dan negatif. Dampak positifnya adalah masyarakat dapat membuang sampahnya pada suatu tempat yang telah disediakan sehingga tidak perlu lagi mencari tempat untuk membuang sampahnya, sedangkan dampak negatifnya adalah kebaradaan TPS ini dapat menimbulkan bau yang tidak sedap, 
pemandangan yang tidak indah, tempat timbulnya bibit penyakit dan lain sebagainya.

\section{Memperoleh Nilai WTP}

Berdasarkan pernyataan dan interval nilai dengan metode Open-Ended Question, diperolah besarnya nilai WTP yang bersedia dibayarkan responden. Dari hasil perhitungan statistik, diperolah rata-rata nilai WTP responden sebesar $\mathrm{Rp} 7.455,-/ \mathrm{KK} /$ bulan. Nilai ini mencerminkan kemampuan responden untuk membayar WTP dengan biaya retribusi pengelolaan sampah sebesar $\mathrm{Rp} 3.000$,/KK/bulan sehingga dilihat dari nilai WTP dan biaya retribusi pengelolaan sampah maka responden mampu untuk membayar kondisi kualitas lingkungan dari keberadaan TPS.

Umumnya responden mengeluarkan biaya untuk membayar atas keberadaan TPS dilihat dari jumlah pendapatan responden. Variabel pendapatan mempunyai pengaruh yang signifikan terhadap WTP sampah rumah tangga (Annisa dkk [5]). WTP untuk peningkatan pengelolaan limbah padat sering dikaitkan dengan standar kehidupan seseorang (Ali dkk [6]). Semakin tinggi pendapatan responden maka semakin besar pula nilai WTP yang dikeluarakan oleh responden.

\section{Menghitung Dugaan Nilai Rataan WTP (Estimating Mean WTP /EWTP)}

Nilai Wi (WTP ke-i) yang didapat dikali oleh fruekuensi relatif untuk mendapatkan dugaan nilai rataan WTP responden seperti contoh perhitungan berikut ini.

$$
\begin{aligned}
\text { EWTP } & =\sum \text { WiPfi } \\
\text { EWTP } & =2000 \times 0,14 \\
& =\text { Rp } 280,- \text { /bulan }
\end{aligned}
$$

Dimana :

$$
\begin{array}{ll}
\text { EWTA } & =\text { Dugaan rataan WTA } \\
\mathrm{Wi} & =\text { Nilai WTA ke-i } \\
\mathrm{Pfi} & =\text { Frekuensi Relatif } \\
\mathrm{n} & =\text { Jumlah responden } \\
\mathrm{i} & =\text { Responden ke-i yang bersedia } \\
\text { melakukan pembayaran jasa lingkungan }
\end{array}
$$

Dengan demikian kelas WTP responden diperoleh dengan menentukan terlebih dahulu nilai terkecil sampai nilai terbesar WTP yang ditawarkan responden. Dari hasil perhitungan diperoleh dugaan nilai rataan WTP (EWTP) sebesar Rp 7.430,-/KK/bulan. Hasil dari dugaan nilai rataan WTP mencerminkan bahwa hasil tersebut benar dan mendekati hasil dari WTP rata-rata yang dikeluarkan oleh responden. 


\section{Memperkirakan Kurva WTP (Estimating Bid Curve)}

Kurva WTP menggambarkan hubungan tingkat WTP (dalam Rp/bulan) dengan jumlah masyarakat (orang). Berdasarkan jawaban yang diperoleh dari responden, didapatkan kurva WTP yang dapat dilihat pada gambar 1 .

Berdasarkan dugaan kurva tawaran WTP dapat dihitung surplus konsumen yang akan diperoleh masyarakat. Surplus konsumen adalah surplus/kelebihan yang diterima responden karena nilai WTP yang dibayarkan lebih tinggi dari pada nilai WTP rata-ratanya.

Hasil dari WTP rata-rata yang dikeluarkan oleh masyarakat sebesar Rp 7.455,-/KK/bulan, sehingga diperoleh rata-rata surplus konsumen yang diterima responden sebesar Rp 230.990,- KK/bulan. Nilai surplus konsumen ini menunjukkan surplus/kelebihan yang diterima responden karena nilai WTP yang diinginkan lebih tinggi dari nilai WTP rata-rata. Adapun contoh perhitungan surplus konsumen berikut ini.

$$
\begin{aligned}
\text { SK } & =\Sigma(\text { WTPi }-\mathrm{P}) \text { dimana WTPi }>\text { P } \\
\text { SK } & =10.000-7.455 \\
& =\text { Rp } 2.545,- \text { KK/bulan }
\end{aligned}
$$

Dimana :

SK = Surplus Konsumen

$$
\begin{array}{ll}
\text { WTPi } & =\text { WTP responden ke-i } \\
\mathrm{P} & =\text { WTP rata-rata }
\end{array}
$$

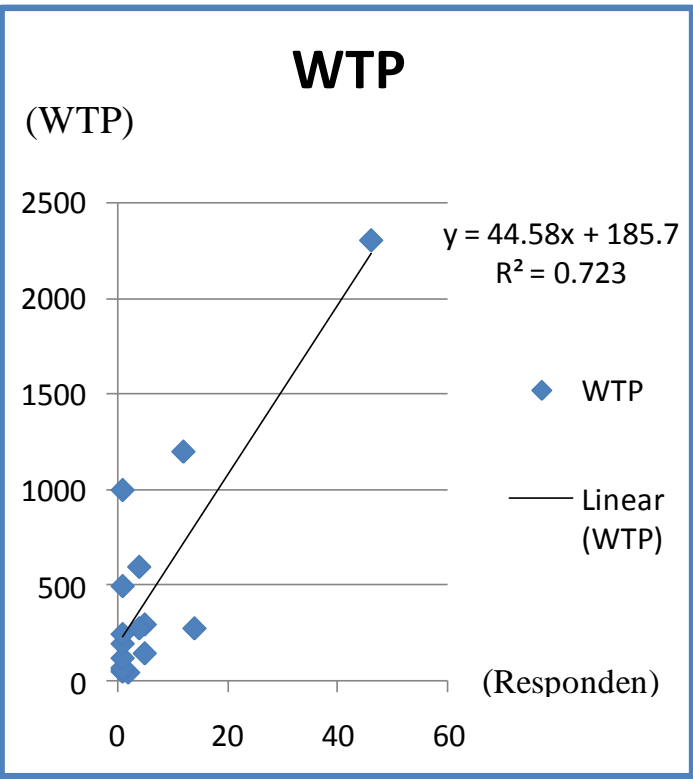

Gambar 1

Dugaan Kurva WTP Responden

\section{WTP Agregat atau Total WTP (TWTP)}

Nilai WTPi (WTP individu sampel ke-i) yang didapat dikali oleh hasil dari pembagian $\mathrm{Ni}$ (jumlah sampel WTP ke-i) dengan N (jumlah sampel) kemudian dikalikan dengan jumlah populasi untuk mendapatkan total WTP responden seperti contoh perhitungan berikut ini.

$$
\begin{aligned}
\text { TWTP } & =\sum_{i}^{n} W T P i\left(\frac{n i}{N}\right) P \\
\text { TWTP } & =2000 \times \frac{14}{100} x 4070 \\
& =\text { Rp } 1.139 .600,-/ \text { bulan }
\end{aligned}
$$

Dimana:

TWTP $=$ Total WTP

WTPi = WTP individu sampel ke-i 
$\mathrm{Ni} \quad=$ Jumlah sampel ke-i yang bersedia membayar sebesar WTP

$$
\begin{array}{ll}
\mathrm{N} & =\text { Jumlah sampel } \\
\mathrm{P} & =\text { Jumlah populasi } \\
\mathrm{I} & =\text { Responden ke-i yang bersedia } \\
\text { membayar pembayaran jasa lingkungan }
\end{array}
$$

Nilai rata-rata WTP responden sebesar $\mathrm{Rp}$ 7.455,-/KK/bulan dari total WTP (TWTP) sebesar Rp 30.240.100,-/bulan. Nilai total WTP ini menunjukkan total dari keseluruhan nilai WTP atas kemampuan responden untuk membayar dari keberadaan TPS per bulan.

\section{Analisis Willingness to Accept \\ Membangun Pasar Hipotesis (Setting-up the Hypothetical Market)}

Berdasarkan pasar hipotesis yang telah dibangun pada saat penelitian dari keberadaan TPS Ciwastra, pihak instansi terkait berencana memberikan ganti rugi kepada masyarakat Kelurahan Mekarjaya atas penurunan kualitas lingkungan akibat keberadaan TPS Ciwastra. Ganti rugi ini berupa dana kompensasi atau perbaikan infrastruktur seperti perbaikan jalan, pengadaan klinik kesehatan, saluran air yang bersih, dan penyemprotan untuk menghilangkan bau yang akan diberikan pihak instansi terkait kepada masyarakat di sekitar lokasi TPS yang terkena dampak negatif.

\section{Memperoleh Nilai WTA}

Berdasarkan pernyataan dan interval nilai yang ditawarkan dalam kuesioner dengan metode Open-Ended Question, maka diperolah besarnya nilai WTA atau dana kompensasi responden. Dari hasil perhitungan statistik, diperolah rata-rata nilai WTA responden sebesar Rp 718.500,- KK/bulan. Nilai ini mencerminkan keinginan responden terhadap nilai WTA, umumnya responden menginginkan dana kompensasi yang tinggi karena dilihat dari jumlah pendapatan responden. Jika semakin rendah pendapatan responden maka semakin tinggi pula nilai WTA yang diinginkan oleh responden. Selain itu, mencerminkan keinginan responden untuk adanya ganti rugi yang berupa perbaikan kondisi dari kualitas lingkungan yang tercemar maupun infrastruktur yang diakibatkan oleh transportasi pengangkut sampah dari keberadaan TPS. Umumnya responden menginginkan dana kompensasi yang tinggi karena biaya hidup yang semakin meningkat.

\section{Menghitung Dugaan Nilai Rataan WTA}

Dengan demikian kelas WTA responden diperoleh dengan menentukan terlebih dahulu nilai terkecil sampai nilai terbesar WTA yang ditawarkan responden. Dari hasil perhitungan diperoleh dugaan nilai rataan WTA (EWTA) sebesar Rp 717.000,-/KK/bulan. Hasil dari dugaan nilai rataan WTA mencerminkan bahwa hasil tersebut benar dan mendekati 
hasil dari WTA rata-rata yang diinginkan oleh responden.

Nilai Wi (WTA ke-i) yang didapat dikali oleh fruekuensi relatif untuk mendapatkan dugaan nilai rataan WTA responden seperti contoh perhitungan berikut ini.

$$
\begin{aligned}
\text { EWTA } & =\sum \text { WiPfi } \\
\text { EWTA } & =250.000 \times 0,010 \\
& =\text { Rp } 2.500,- \text { /bulan }
\end{aligned}
$$

Dimana :

$$
\begin{array}{ll}
\text { EWTA } & =\text { Dugaan rataan WTA } \\
\mathrm{Wi} & =\text { Nilai WTA ke-i } \\
\mathrm{Pfi} & =\text { Frekuensi Relatif } \\
\mathrm{n} & =\text { Jumlah responden } \\
\mathrm{i} & =\text { Responden ke-i yang bersedia }
\end{array}
$$
melakukan pembayaran jasa lingkungan

\section{Memperkirakan Kurva WTA (Estimating Bid Curve)}

Kurva ini menggambarkan hubungan tingkat WTA (dalam Rp/bulan) dengan jumlah responden (orang).

Berdasarkan dugaan kurva tawaran WTA dapat dihitung surplus konsumen yang akan diperoleh masyarakat. Surplus konsumen adalah surplus/kelebihan yang diterima responden karena nilai WTA yang diinginkan lebih tinggi dari pada nilai WTA rata-ratanya
Hasil dari WTA rata-rata yang diterima oleh responden sebesar $\mathrm{Rp} 718.500,-/ \mathrm{KK} /$ bulan, sehingga diperoleh rata-rata surplus konsumen yang diterima responden sebesar Rp 6.027.000,- KK/bulan. Nilai surplus konsumen ini menunjukkan surplus/kelebihan yang diterima responden karena nilai WTA yang diinginkan lebih tinggi dari nilai WTA rata-rata. Adapun contoh perhitungan surplus konsumen berikut ini.

$$
\begin{aligned}
\text { SK } & =\Sigma(\text { WTA }-\mathrm{P}) \text { dimana WTAi }>\mathrm{P} \\
\mathrm{SK} & =750.000-718.500 \\
& =\mathrm{Rp} 31.500,-\mathrm{KK} / \text { bulan }
\end{aligned}
$$

Dimana :

SK = Surplus Konsumen

WTAi = WTA responden ke- $\mathrm{i}$

$\mathrm{P} \quad=$ WTA rata-rata

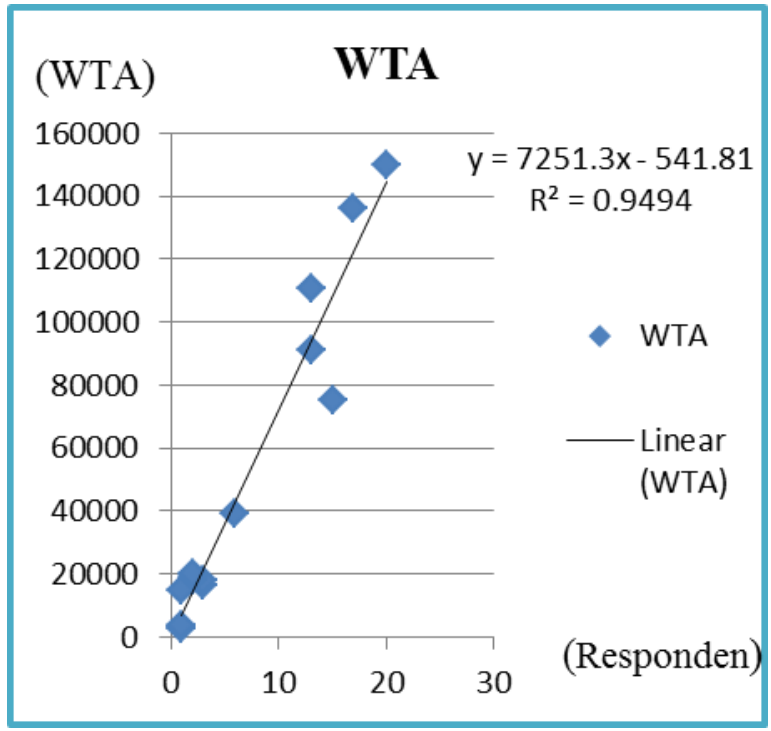

Gambar 2

Dugaan Kurva WTA Responden 


\section{WTA Agregat atau Total WTA (TWTA)}

Nilai WTAi (WTA individu sampel ke-i) yang didapat dikali oleh hasil dari pembagian $\mathrm{Ni}$ (jumlah sampel WTP ke-i) dengan N (jumlah sampel) kemudian dikalikan dengan jumlah populasi untuk mendapatkan total WTA responden.

Nilai rata-rata WTA responden sebesar Rp 718.500,-/KK/bulan dari total WTA (TWTA) sebesar Rp 2.918.190.000,-/bulan. Nilai total WTA ini menunjukkan total dari keseluruhan nilai WTA atas keinginan responden untuk menerima dana kompensasi dari keberadaan TPS per bulan. Adapun contoh perhitungan total WTA responden berikut ini.

$$
\begin{aligned}
\text { TWTA } & =\sum_{i}^{n} W T A i\left(\frac{n i}{W}\right) P \\
\text { TWTP } & =250.000 \times \frac{1}{100} \times 4070 \\
& =\text { Rp } 10.175 .000,-/ \text { bulan }
\end{aligned}
$$

Dimana:

$$
\begin{array}{ll}
\text { TWTA } & =\text { Total WTA } \\
\text { WTAi } & =\text { WTA individu sam } \\
\mathrm{Ni} \quad=\text { Jumlah sampel } \\
\text { membayar sebesar WTA } \\
\mathrm{N} \quad=\text { Jumlah sampel } \\
\mathrm{P} \quad=\text { Jumlah populasi }
\end{array}
$$$$
\text { WTAi }=\text { WTA individu sampel ke- } \mathrm{i}
$$$$
\mathrm{Ni} \quad=\text { Jumlah sampel ke-i yang bersedia }
$$

\section{Nilai Ekonomi TPS Ciwastra}

Nilai ekonomi dari TPS Ciwastra berdasarkan metode contingent valuation method didapatkan dengan mengalikan surplus konsumen dengan jumlah populasi kepala keluarga Kelurahan Mekarjaya sebesar 4.070 KK. Sehingga dari hasil tersebut didapat nilai ekonomi TPS Ciwastra sebesar Rp 940.129.300,-. Dari nilai ekonomi tersebut menggambarkan harga pasar ekonomi sebagai upaya pelestarian lingkungan dan proses peningkatan kesejahteraan masyarakat yang berada di lingkungan TPS Ciwastra tersebut. Dari nilai tersebut peran valuasi ekonomi terhadap pengelolaan sumber daya alam dan lingkungan sangat penting dalam penentuan suatu kebijakan pembangunan.

\section{KESIMPULAN}

Dari penelitian yang telah dilakukan dapat diambil kesimpulan sebagai berikut:

1. Berdasarkan hasil perhitungan maka diketahui kesediaan responden untuk membayar (WTP) penduduk Kelurahan Mekarjaya Kecamatan Rancasari Kota Bandung dari rata-rata WTP responden sebesar Rp 7.455,-/KK/bulan dan nilai total WTP responden sebesar Rp 30.240.100,-/bulan, sehingga surplus konsumen yang diterima oleh masyakat sebesar Rp 230.990,- KK/bulan. Hasil perhitungan nilai WTP menunjukkan bahwa responden mampu untuk membayar lebih besar daripada biaya retribusi yang ditetapkan yaitu sebesar Rp 3.000,-/KK/bulan. Hal ini dapat digunakan sebagai dasar dalam upaya 
perbaikan pengelolaan persampahan di TPS Ciwastra.

2. Berdasarkan hasil perhitungan maka diketahui kesediaan untuk menerima dana kompensasi (WTA) penduduk Kelurahan Mekarjaya Kecamatan Rancasari Kota Bandung dari rata-rata WTA responden sebesar $\mathrm{Rp} 718.500$,/KK/bulan dan nilai total WTA responden sebesar Rp 2.918.190.000,-/bulan, sehingga surplus konsumen yang diterima oleh masyakat sebesar $\mathrm{Rp}$ 6.027.000,- KK/bulan.

3. Nilai ekonomi dari keberadaan TPS Ciwastra sebesar Rp 940.129.300,-. Nilai ekonomi tersebut menggambarkan harga pasar ekonomi sebagai upaya pelestarian lingkungan dan proses peningkatan kesejahteraan masyarakat yang berada di lingkungan TPS Ciwastra tersebut. Dari nilai tersebut peran valuasi ekonomi terhadap pengelolaan sumber daya alam dan lingkungan sangat penting dalam penentuan suatu kebijakan pembangunan.

\section{DAFTAR PUSTAKA}

[1] Meidiana, C. dan Gamse, T. "Development of Waste Management Practices in Indonesia", European Journal of Scientific Research ISSN 1450-216X Vol.40 No.2, pp.199-210, 2010.

[2] PD Kebersihan Kota Bandung.
"Laporan Kinerja PD Kebersihan Kota Bandung", 2015

[3] Susanto, I. dan Rahardyan, B. "Analisis Penerimaan Retribusi Sampah oleh Masyarakat dalam Upaya Peningkatan Pelayanan Pengelolaan Persampahan di Kota Bandung Bagian Timur". Jurnal Perencanaan Wilayah dan Kota (Journal of Regional and City Planning) vol. 27, no. 3, pp. 219-235, 2016.

[4] Ruban, A. Putri, EIK. Ikayan, M. "Willingness To Pay Masyarakat Terhadap Pengolahan Sampah Ramah Lingkungan Di Tpa Dusun Toisapu, Kota Ambon". Jurnal ekonomi pertanian, sumberdaya dan lingkungan 2014.

[5] Annisa, S. Kadir, H. dan Mardiana. "Analisis Willingness To Pay (WTP) Sampah Rumah Tangga (Studi Kasus Perumnas Kelurahan Simpang Baru Panam Pekanbaru)". JOM FEKON Vol. 2 No. 1, 2015.

[6] Ali, H. Ali, N. Ahmad, AR. Ibrahim, M. Ahmad S dan Yaacob, S. "Solid Waste Management and the Willingness To Pay for Improved Services towards Achieving Sustainable Living". Advances in Natural and Applied Sciences, 6(1): 52-60, 2012. 